\title{
Cytokeratin expression in epidermal stem cells in skin adnexal tumors
}

\author{
XIAOQIU ZHOU ${ }^{1}$, GUOYONG LI ${ }^{2}$, DONGGUAN WANG ${ }^{1}$, XIYIN SUN ${ }^{1}$ and XINGONG LI ${ }^{1}$ \\ Departments of ${ }^{1}$ Pathology and ${ }^{2}$ Stomatology, Dongying People's Hospital, Dongying, Shandong 257091, P.R. China
}

Received April 25, 2018; Accepted October 31, 2018

DOI: $10.3892 / \mathrm{ol} .2018 .9679$

\begin{abstract}
The expression levels of seven types of cytokeratin (CK) in different kinds of skin adnexal tumors were evaluated. One hundred and thirty-two patients with different kinds of skin adnexal tumors admitted and treated in the Department of Dermatology of Dongying People's Hospital from May 2013 to May 2015 were selected and underwent tissue section staining. Another 20 cases of normal skin were enrolled as the control group. The expression levels of the seven types of CK in different kinds of skin appendages were observed and recorded. The expression levels of the seven types of CK in the 132 cases of skin adnexal tumor tissues were different. CK10 was mainly expressed in squamous cell carcinoma, but it was not expressed in basal cell carcinoma. CK19 was expressed in basal cell carcinoma, but its expression was not detected in squamous cell carcinoma. As the degree of differentiation was increased in the epidermis, hair follicle and sebaceous gland, the expressed molecular weight of CK was augmented gradually. The expression levels of five types of CK (namely, CK8, CK10, CK14, CK18 and CK19) could be measured in the squamous cell carcinoma and basal cell carcinoma. Statistical analysis revealed that there were statistically significant differences in the expression levels of these five types of CK in the two cell carcinomas $(\mathrm{P}<0.05)$. Five types of CK, i.e., CK7, CK8, CK17, CK18 and CK19, had markedly different expression levels in hair follicle tumor and sweat gland tumor, which were statistically significant $(\mathrm{P}<0.05)$. The expression levels of a group of CKs detected by virtue of semi-quantitative analysis via immunohistochemistry can be regarded as one of the important indexes for clinical diagnosis of skin adnexal tumors.
\end{abstract}

\section{Introduction}

As an organ with the largest distribution area in the human body, the skin can be studied systematically by means of multiple techniques at present, and the content has been fairly

Correspondence to: Dr Xiaoqiu Zhou, Department of Pathology, Dongying People's Hospital, 317 Nanyi Road, Dongying, Shandong 257091, P.R. China

E-mail: zhon7407@163.com

Key words: skin tumor, cytokeratin, immunohistochemical staining intensive. Currently, the differentiation and morphological characteristics of various types of skin tumors are thoroughly understood. However, a brand-new concept of immunoarchitecture has been proposed in recent years, which mainly refers to the structures of various types of tissues that can be marked and shown via immunohistochemical staining (1). Corresponding antibodies to varied organs to be labeled should be selected. For example, the markers of lymphocytes, vascular endothelial cells and mononuclear macrophages are generally utilized in research of immunoarchitecture of the lymphoid tissue (2). In case of studying the immunoarchitecture of the skin tissue, the markers of a variety of interstitial cells are adopted, of which cytokeratin (CK) is the most important type (3). Some scholars have discovered in their studies that $\mathrm{CK}$ can be considered as a specific marker of the epithelial cells. $\mathrm{CK}$ in a particular type of epithelium may be arranged in intermediate filaments according to certain rules, and such arrangement constitutes the CK composition type in the particular type of epithelium (4). A study of Damavandy et al indicated that different types of $\mathrm{CK}$ are expressed in different kinds of epithelial cells. In addition, different CKs are expressed in varied differentiation stages of the same kind of epithelial cells (5). Moreover, it was also discovered that $\mathrm{CK}$ expression in the epithelial cells may change due to different lesions occurring, but the specific CK composition type is not changed, and that corresponding CKs are still expressed in tumors with differentiation features of a certain epithelial structure (6). Therefore, selecting appropriate CKs to label the epithelium of the skin can identify the occurrence of tumors and determine the differentiation directions of the tumor components, which is conducive to diagnosing the histopathological classification of the tumors in clinical application.

\section{Patients and methods}

Patients data. A total of 132 patients with different kinds of skin adnexal tumors admitted and treated in the Department of Dermatology of Dongying People's Hospital (Dongying, China) from May 2013 to May 2015 were selected, including 38 cases of hair follicle tumor, 36 cases of sweat gland tumor, 30 cases of basal cell carcinoma, 24 cases of squamous cell carcinoma and 4 cases of adenoma sebaceum. The normal skin of 40 healthy adults was enrolled as the control group. The study was approved by the Ethics Committee of Dongying People's Hospital (Dongying, China) and informed consents were signed by the patients or guardians. 
Table I. CK expression levels in normal skin tissues.

\begin{tabular}{|c|c|c|c|c|c|c|c|}
\hline Items & CK7 & CK8 & CK10 & CK14 & CK17 & CK18 & CK19 \\
\hline \multicolumn{8}{|l|}{ Epidermis } \\
\hline Stratum corneum & ++ & - & +++ & + & + & - & - \\
\hline Granular layer & + & - & +++ & ++ & ++ & + & - \\
\hline Superficial spinous layer & + & - & +++ & ++ & ++ & + & - \\
\hline Deep spinous layer & + & - & +++ & + & ++ & ++ & - \\
\hline Basal layer & + & + & - & + & ++ & + & + \\
\hline \multicolumn{8}{|l|}{ Sweat gland } \\
\hline Epidermal portion of duct & + & - & - & ++ & + & +++ & ++ \\
\hline Dermal portion of duct & + & + & - & ++ & + & +++ & ++ \\
\hline Secretory portion & ++ & + & - & + & ++ & +++ & +++ \\
\hline \multicolumn{8}{|l|}{ Sebaceous gland } \\
\hline Duct portion & + & - & ++ & ++ & + & + & - \\
\hline Secretory portion & ++ & - & + & + & + & - & + \\
\hline Basaloid cell & + & - & + & + & ++ & - & + \\
\hline \multicolumn{8}{|l|}{ Hair } \\
\hline Hair shaft & ++ & - & +++ & + & + & - & - \\
\hline Outer root sheath & - & + & - & ++ & ++ & - & +++ \\
\hline Inner root sheath & ++ & - & + & + & ++ & - & - \\
\hline Hair bulb & - & - & - & + & - & - & +++ \\
\hline
\end{tabular}

Table II. CK expression levels in epidermal tumors (semi-quantitative scoring).

\begin{tabular}{lcccccccc}
\hline Items & $\mathrm{n}$ & $\mathrm{CK} 7$ & $\mathrm{CK} 8$ & $\mathrm{CK} 10$ & CK14 & CK17 & CK18 & CK19 \\
\hline Basal cell carcinoma & 30 & 0 & 6 & 0 & 6 & 8 & 4 & 8 \\
Squamous cell carcinoma & 24 & 0 & 4 & 6 & 4 & 6 & 4 & 0 \\
\hline
\end{tabular}

Instruments and consumables. Paraffin section slicer (Leica Biosystems, Shanghai, China), paraffin embedding machine (Leica Biosystems), pathological image analysis system (Motic, Xiamen, China), light microscope (Olympus, Tokyo, Japan), ready-to-use and shortcut immunohistochemistry kit (Shanghai Bangyi Biotechnology Co., Ltd., Shanghai, China), kit for enhanced diaminobenzidine (DAB) development (Shanghai LMAI Biotechnology Co., Ltd., Shanghai, China), rabbit anti-human CK monoclonal antibodies (Proteintech, Wuhan, China), goat anti-rabbit secondary antibodies (Proteintech) and hematoxylin (Shanghai Xinfan Biotech Co., Ltd., Shanghai, China).

Immunohistochemical staining methods. The skin in both the experimental case and control groups was fixed with $10 \%$ formaldehyde at $20^{\circ} \mathrm{C}$ for $24 \mathrm{~h}$ and then embedded in paraffin and then sliced to $4-\mu \mathrm{m}$-thick sections. After dewaxing and rehydration, the sections were washed with phosphate-buffered saline (PBS). Next, the sections were sealed in $5 \%$ milk at $20^{\circ} \mathrm{C}$ for $15 \mathrm{~min}$, followed by addition of primary antibody solution polyclonal antibodies of CK7, CK8, CK10, CK14, CK17, CK18 and CK19 (dilution, 1:50; cat. nos. 17513-1-AP, 17514-1-AP, 18343-1-AP, 10143-1-AP, 17516-1-AP, 10830-1-AP,
Table III. CK expression levels in squamous cell carcinomas of the skin, lung and esophagus (positive cases/observed cases).

\begin{tabular}{lrcccc}
\hline Items & $\mathrm{n}$ & CK7 & CK10 & CK17 & CK19 \\
\hline Skin & 24 & $2 / 24$ & $24 / 24$ & $24 / 24$ & $2 / 24$ \\
Lung & 6 & $2 / 6$ & $4 / 6$ & $4 / 6$ & $0 / 6$ \\
Esophagus & 8 & $2 / 8$ & $8 / 8$ & $6 / 8$ & $0 / 8$
\end{tabular}

10712-1-AP; Proteintech) for incubation in a refrigerator at $4^{\circ} \mathrm{C}$ overnight. After washing with PBS, the goat anti-rabbit secondary polyclponal antibody solution (dilution, 1:1,000; cat. no. SA00001-2; Proteintech) was added and incubated for half an hour, followed by washing again. After that, streptavidin-peroxidase solution was adopted for incubation at room temperature for half an hour, and then the sections were washed. Next, the enhanced DAB staining was performed for color development, and the sections were washed three times. After counterstaining with the hematoxylin solution, the sections were mounted with neutral balsam and then observed and counted under an inverted light microscope (Olympus). 
Table IV. CK expression levels in hair follicle tumors and adenoma sebaceums (semi-quantitative scoring).

\begin{tabular}{lrccccccc}
\hline Items & $\mathrm{n}$ & $\mathrm{CK} 7$ & $\mathrm{CK} 8$ & $\mathrm{CK} 10$ & $\mathrm{CK} 14$ & $\mathrm{CK} 17$ & $\mathrm{CK} 18$ & CK19 \\
\hline Hair follicle tumor & & & & & & & & \\
$\quad$ Trichofolliculoma & 4 & 6 & 0 & 0 & 8 & 8 & 0 & 8 \\
Pilomatricoma & 18 & 0 & 0 & 0 & 4 & 9 & 4 & 4 \\
Trichoblastoma & 2 & 0 & 4 & 0 & 6 & 6 & 0 & 6 \\
Tricholemmoma & 6 & 0 & 0 & 0 & 6 & 6 & 0 & 0 \\
Trichilemmal carcinoma & 8 & 0 & 0 & 0 & 8 & 8 & 0 & 0 \\
Adenoma sebaceum & 4 & 0 & 6 & 6 & 6 & 6 & 0 & 8 \\
$\quad$ Sebaceous carcinoma & 4 & & & & & & &
\end{tabular}

Table V. CK expression levels in sweat gland tumors (semi-quantitative scoring).

\begin{tabular}{lcccccccc}
\hline Items & $\mathrm{n}$ & $\mathrm{CK} 7$ & $\mathrm{CK} 8$ & $\mathrm{CK} 10$ & $\mathrm{CK} 14$ & $\mathrm{CK} 17$ & CK18 & CK19 \\
\hline Papillary eccrine adenoma & 10 & 8 & 0 & 0 & 6 & 8 & 8 & 8 \\
Eccrine spiradenoma & 6 & 8 & 6 & 0 & 0 & 0 & 6 & 6 \\
Clear cell hidroadenoma & 8 & 6 & 6 & 0 & 8 & 6 & 0 & 6 \\
Tubulopapillary hidroadenoma & 2 & 8 & 4 & 0 & 8 & 4 & 6 & 8 \\
Papillary cystadenocarcinoma of sweat gland & 4 & 6 & 4 & 0 & 8 & 4 & 6 & 8 \\
Chondroid syringoma & 6 & 6 & 4 & 4 & 6 & 0 & 0 & 4 \\
\hline
\end{tabular}

Evaluation of experimental results. A total of 100 cells were randomly counted in each field of vision to be observed, and the average number of cells in the field of vision was calculated as the number of positive cells expressing such proteins in the tissues. Score of color depth: 0 point (no staining), 1 point (weak staining) and 2 points (strong staining). Score of positive rate of stained cells: 1 point (proportion of positive cells of $1-25 \%), 2$ points $(26-50 \%), 3$ points $(51-75 \%)$ and 4 points (76-100\%). The score of color depth was multiplied by the score of positive rate, and the final result of 0-2 points stood for (-), 4 points for $(+), 6$ points for $(++)$ and 8 points for $(+++)$. The rounded score was classified into the closest grade.

Statistical analysis. Statistical Product and Service Solutions (SPSS) 19.0 software was adopted for data analysis. Chi-square test and t-test were performed for statistical analyses of enumeration data and measurement data, respectively. $\alpha=0.05$ was considered as the test and statistical standard.

\section{Results}

CK expression levels in normal skin. CKs could be expressed in several parts of the skin tissues, such as epidermis and appendage. In this study, it was discovered that the expression levels of CK17, CK18 and CK19 existed in the basal cells of the epidermis, while the expression of CK10 was only detected in the prickle cell and granular layers. It was also indicated that in the processes of differentiation and maturation of the tissue cells in each skin layer, the molecular weight of CK was gradually increased. CK8 was not expressed in the epidermal layer of the sweat duct, and CK10 was not expressed in the duct portion and secretory portion. The molecular weight of
CK was augmented with the gradual differentiation and maturation of the hair shaft (Table I).

CK expression levels in epithelial tumors of the skin. CK10 was mainly expressed in squamous cell carcinoma, but it was not expressed in basal cell carcinoma. CK19 was expressed in basal cell carcinoma, but its expression was not detected in squamous cell carcinoma (Table II).

Massive CK10 and CK17 expression levels could be detected in the squamous cell carcinomas of the skin, lung and esophagus. However, CK7 and CK19 were not expressed in the squamous cell carcinomas of the lung and esophagus, and they were expressed in few cases of skin squamous cell carcinoma, with no statistical significance (Table III).

Apparent CK14 and CK17 expression levels could be detected in a majority of hair follicle tumors, but CK19 was expressed in pilomatricoma, trichofolliculoma and trichoblastoma (Table IV).

CK10 was rarely expressed in sweat gland tumors, and the $\mathrm{CK}$ expression levels varied in different portions. In papillary eccrine adenoma, the expression levels of CK7, CK17, CK18 and CK19 were mainly detected (Table V).

As shown in Table VI, the quantities of cells with positive CK expression levels were different among different skin adnexal tumors. Moreover, the expression intensities of different types of CK varied in the same kind of skin adnexal tumors.

The differences in CK7 and CK17 expression levels in squamous cell carcinoma and basal cell carcinoma were not statistically significant. The expression levels of five types of CK (namely, CK8, CK10, CK14, CK18 and CK19) could be measured in squamous cell carcinoma and basal cell carcinoma. Statistical analysis revealed that there were statistically 
Table VI. Quantities of cells with positive CK expression levels in epithelial tumors of the skin.

\begin{tabular}{lcccccccc}
\hline Items & $\mathrm{n}$ & $\mathrm{CK} 7$ & $\mathrm{CK} 8$ & $\mathrm{CK} 10$ & CK14 & CK17 & CK18 & CK19 \\
\hline Basal cell carcinoma & 30 & - & Medium & - & Medium & Large & - & Medium \\
Squamous cell carcinoma & 24 & - & Small & Medium & Small & Medium & Small & - \\
Sweat gland tumor & & & & & & & & \\
$\quad$ Papillary eccrine adenoma & 10 & Large & Medium & - & Medium & Medium & Large & Large \\
Eccrine spiradenoma & 6 & Large & Medium & - & Large & Medium & Medium & Medium \\
Clear cell hidroadenoma & 8 & Large & Large & - & Large & Large & Small & Large \\
Tubulopapillary hidroadenoma & 2 & Large & Medium & Small & Large & Medium & Medium & Large \\
Papillary cystadenocarcinoma of sweat gland & 4 & Large & Medium & - & Large & Medium & Medium & Large \\
Chondroid syringoma & 6 & Medium & Medium & Small & Large & Small & Small & Medium \\
Hair follicle tumor & & & & & & & & \\
$\quad$ Trichofolliculoma & 4 & Medium & Medium & Small & Large & Large & Medium & Large \\
Pilomatricoma & 18 & - & Small & Small & Medium & Large & Medium & Medium \\
Trichoblastoma & 2 & - & Medium & Small & Large & Medium & - & Medium \\
Tricholemmoma & 6 & Small & Small & Small & Large & Large & - & Small \\
Trichilemmal carcinoma & 8 & Small & Small & Small & Large & Large & - & Small \\
Adenoma sebaceum & & & & & & & &
\end{tabular}

Table VII. Comparison of CK expression levels in squamous cell carcinoma and basal cell carcinoma of the skin.

\begin{tabular}{lcccccccc}
\hline Items & $\mathrm{n}$ & CK7 & CK8 & CK10 & CK14 & CK17 & CK18 & CK19 \\
\hline Squamous cell carcinoma & 24 & $0.41 \pm 0.816$ & $3.84 \pm 0.269$ & $6.95 \pm 1.275$ & $4.26 \pm 0.805$ & $7.97 \pm 1.372$ & $4.06 \pm 0.281$ & $0.35 \pm 1.093$ \\
Basal cell carcinoma & 30 & $0.39 \pm 0.749$ & $5.93 \pm 1.148$ & $0.34 \pm 0.742$ & $6.43 \pm 1.296$ & $8.42 \pm 1.592$ & $0.23 \pm 0.741$ & $7.92 \pm 1.505$ \\
\hline
\end{tabular}

Table VIII. Comparison of CK expression levels in hair follicle tumors and sweat gland tumors.

\begin{tabular}{|c|c|c|c|c|c|c|c|c|}
\hline Items & $\mathrm{n}$ & CK7 & CK8 & CK10 & CK14 & CK17 & CK18 & CK19 \\
\hline Hair follicle tumor & 38 & $0.94 \pm 1.842$ & $0.83 \pm 1.375$ & $0.15 \pm 0.642$ & $5.70 \pm 2.814$ & $8.04 \pm 1.592$ & $2.14 \pm 2.104$ & $3.18 \pm 2.748$ \\
\hline Sweat gland tumor & 36 & $7.38 \pm 2.104$ & $4.28 \pm 1.895$ & $0.14 \pm 0.695$ & $5.66 \pm 3.104$ & $4.89 \pm 2.485$ & $4.28 \pm 3.185$ & $7.23 \pm 1.596$ \\
\hline
\end{tabular}

significant differences in the expression levels of these five types of CK in the two cell carcinomas $(\mathrm{P}<0.05)$ (Table VII).

The expression levels of CK10 and CK14 could be definitely detected in hair follicle tumors and sweat gland tumors, but the differences in the two types of CK expression levels in hair follicle tumors and sweat gland tumors were not statistically significant ( $p>0.05$ ). Five types of CK, i.e., CK7, CK8, CK17, CK18 and CK19, had markedly different expression levels in the hair follicle tumors and sweat gland tumors, which were statistically significant $(\mathrm{P}<0.05)$ (Table VIII).

\section{Discussion}

There are plenty of cytoskeletal protein components in the cytoplasm of mammals, and it has been manifested that the cytoskeletal proteins mainly exist in the cytoplasm of the epithelial cells, which are dominated by actin, tubulin and cytokeratin (CK) (7). CK, as a specific marker of the epithelial cells, can be divided into as many as 20 types according to its molecular weight. Furthermore, it can be classified into type I and type II, of which the former has a relatively low molecular weight and location at chromosome 17q12-21 and contains CK10-CK20. Type II CK possesses a higher molecular weight and is located at chromosome 12q11-12, and CK1-CK9 belong to type II CK (8). Dehner et al have demonstrated that CKs in specific epithelial cells as well as CKs in cells differentiating towards such epithelial cells can form intermediate filaments in the body, whose combination mode is the CK composition type of such epithelial cells (9).

The hair, sebaceous gland and sweat gland of human belong to the skin appendages. Most previous studies focused on the exploration of CK expression levels in various types of 
epithelial components of the skin, but there are great differences in the experimental results, and no consensus has been reached $(10,11)$. Since no studies have been conducted for the immunoarchitecture of the skin so far, such architecture still remains unknown. Lin et al (12) discovered that CK5, CK8 and CK14 can be expressed in the sweat gland tissues, while only CK5 and CK14, instead of CK8, can be expressed in the sebaceous gland. El-Khoury et al (13) revealed that different types of CK expression levels are present in different hair structures. For instance, CK15 expression exists in the hair bulb stem cells, CK1 and CK10 expression levels are present in the inner root sheath of the hair follicle, CK14 and CK15 expression levels are detectable in the outer layer of the outer root sheath, and CK6, CK16 and CK17 expression levels exist in the inner layer of the outer root sheath, which are consistent with the results of this study. In addition, according to this study, plenty of CK7, CK17, CK18 and CK19 expression levels were measured in the sweat gland, more expression levels of CK7, CK10, CK17 and CK19 were detected in the sebaceous gland, a relatively large amount of CK14 expression was present in the hair bulb stem cells, more CK7 and CK14 expression levels were observed in the inner root sheath, and more CK14 and CK19 were expressed in the outer root sheath. The above suggested that the CK expression profiles in various kinds of skin appendages in this study are wider than those in previous literature. Moreover, there were many overlapping CK expression levels, implying that the skin appendages may be generated, differentiated and maturated from the same tissue. They may be a category of derivatives of the epidermal stem cells, which differentiate towards different directions and finally form a variety of tissues and structures.

Jakobiec et al (14) applied CK15 expression to investigate the property of the adenoma sebaceum, and Andruszkow et al (15) utilized CK19 expression for differential diagnosis of the basal cell carcinoma and adenoma sebaceum. Furthermore, it is reported that $\mathrm{CK}$ expression levels can be used to diagnose clear cell hidroadenoma (16) and primary neuroendocrine carcinoma (17) clinically, suggesting that detection of CKs may be beneficial to diagnosing epithelial tumor of the skin. In this study, comprehensive analyses on the experimental results were performed by virtue of the semi-quantitative scoring method via immunohistochemistry, and the findings were in line with partial results of previous studies.

In conclusion, the expression levels of a group of CKs detected by virtue of semi-quantitative analysis via immunohistochemistry can be regarded as one of the important indexes for clinical diagnosis of skin adnexal tumors.

\section{Acknowledgements}

Not applicable.

\section{Funding}

No funding was received.

\section{Availability of data and materials}

The datasets used and/or analyzed during the current study are available from the corresponding author on reasonable request.

\section{Authors' contributions}

XZ collected the tissue. XZ, GL, DW and XS were responsible for immunohistochemical staining. XZ and XL helped with statistical analysis. The manuscript was written through contributions of all authors. All authors read and approved the final manuscript.

\section{Ethics approval and consent to participate}

The study was approved by the Ethics Committee of Dongying People's Hospital (Dongying, China) and informed consents were signed by the patients or guardians.

\section{Patient consent for publication}

Not applicable.

\section{Competing interests}

The authors declare that they have no competing interests.

\section{References}

1. Rao RS, Patil S and Ganavi BS: Oral cytokeratins in health and disease. J Contemp Dent Pract 15: 127-136, 2014.

2. Sidney LE, McIntosh OD and Hopkinson A: Phenotypic change and induction of cytokeratin expression during in vitro culture of corneal stromal cells. Invest Ophthalmol Vis Sci 56: 7225-7235, 2015.

3. Dai Y, Qu W, Sang S, Tao S, Li Y, Wang Y, Li Q, Wu T, Zhu A, Chen Q, et al: Reference intervals of cytokeratin-19 fragment (CYFRA 21-1) in healthy adults in China. Clin Lab 64: 123-133, 2018.

4. Nayak KK and Gupta P: Study of the keratin-based therapeutic dermal patches for the delivery of bioactive molecules for wound treatment. Mater Sci Eng C 77: 1088-1097, 2017.

5. Damavandy AA, Terushkin V,Zitelli JA, Brodland DG, Miller CJ, Etzkorn JR, Shin TM, Cappel MA, Mitkov M and Hendi A: Intraoperative immunostaining for cytokeratin-7 during Mohs micrographic surgery demonstrates low local recurrence rates in extramammary Paget's disease. Dermatol Surg 44: 354-364, 2018.

6. Khanom R, Nguyen CT, Kayamori K, Zhao X, Morita K, Miki Y, Katsube K, Yamaguchi A and Sakamoto K: Keratin 17 is induced in oral cancer and facilitates tumor growth. PLoS One 11: e0161163, 2016.

7. Gheini $\mathrm{MH}$ and Jalayer Naderi N: The relationship between cytokeratins 7 and 20 expression, and prognostic factors in colon adenocarcinoma: An immunohistochemical study. Iran J Pathol 12: 94-98, 2017.

8. Kolivras A, Thompson N and Thompson C: Loss of cytokeratin-15 (CK15) expression is not specific for lichen planopilaris (LPP). J Am Acad Dermatol 75: 428-429, 2016.

9. Dehner C, Rötzer V, Waschke J and Spindler V: A desmoplakin point mutation with enhanced keratin association ameliorates pemphigus vulgaris autoantibody-mediated loss of cell cohesion. Am J Pathol 184: 2528-2536, 2014

10. Cai X, Li J, Yuan X, Xiao J, Dooley S, Wan X, Weng H and Lu L: CD133 expression in cancer cells predicts poor prognosis of non-mucin producing intrahepatic cholangiocarcinoma. J Transl Med 16: 50, 2018.

11. Hulst AG, Verstappen DR, van der Riet-Van Oeveren D, Vermeulen NP and Noort D: Mass spectrometric identification of isocyanate-induced modifications of keratins in human skin. Chem Biol Interact 237: 141-150, 2015.

12. Lin XY, Zhang H, Tang N, Zhang XP, Zhang W, Wang EH and Han YC: Expression and diagnostic implications of carbonic anhydrase IX in several tumours with predominantly clear cell morphology. Histopathology 66: 685-694, 2015. 
13. El-Khoury J, Renald MH, Plantier F, Avril MF and MoyalBarracco M: Vulvar hidradenoma papilliferum (HP) is located on the sites of mammary-like anogenital glands (MLAGs): Analysis of the photographs of 52 tumors. J Am Acad Dermatol 75: 380-384, 2016.

14. Jakobiec FA, Rai R and Lefebvre DR: Papillary hidradenoma of the eyelid margin: clinical and immunohistochemical observations further supporting an apocrine rather than an eccrine origin. Surv Ophthalmol 59: 540-547, 2014.

15. Andruszkow JH, Oll M, Förster S, Knüchel R and Jäkel J: p40 in conjunction with CK20 and E-cadherin distinguishes primary adnexal neoplasms of the skin. Appl Immunohistochem Mol Morphol 24: 414-421, 2016.
16. Au B, Sidiropoulos KG, Ghazarian D and Sidiropoulos M: Lymph node involvement by a clear cell nodular hidradenoma-like tumor of uncertain malignant potential. Am J Dermatopathol 39: 953-954, 2017.

17. Yang $\mathrm{X}$, Zhang D, Chong T, Li Y, Wang $Z$ and Zhang $\mathrm{P}$ : Expression of CK19, CD105 and CD146 are associated with early metastasis in patients with renal cell carcinoma. Oncol Lett 15: 4229-4234, 2018

(c) (1) () This work is licensed under a Creative Commons EY No NO Attribution-NonCommercial-NoDerivatives 4.0 International (CC BY-NC-ND 4.0) License. 